Saif Munther Borgan, MD

Department of Endocrinology, Diabetes, and Metabolism, Cleveland Clinic, Cleveland, $\mathrm{OH}$
Leila Zeinab Khan, MD

Medical Director, Calcium and Parathyroid Center, Department of Endocrinology, Diabetes, and Metabolism, Cleveland Clinic; Clinical Assistant Professor of Medicine, Cleveland Clinic Lerner College of Medicine of Case Western Reserve University, Cleveland, $\mathrm{OH}$
Vinni Makin, MD, FACE

Director, East Region, Department of Endocrinol-

ogy, Diabetes, and Metabolism, Cleveland Clinic;

Assistant Professor of Medicine, Cleveland Clinic

Lerner College of Medicine of Case Western

Reserve University, Cleveland, $\mathrm{OH}$

\title{
Hypercalcemia and vitamin $A$ : A vitamin to keep in mind
}

\section{ABSTRACT}

Vitamin A, like many things in life, should be consumed in appropriate amounts. Excessive intake of preformed vitamin $A$, such as that found in supplements and animal sources (animal liver, fish liver oil, dairy, and eggs), is associated with multisystem effects that can include bone resorption and hypercalcemia. Hence, vitamin A toxicity should be explored in unexplained cases of parathyroid hormone-independent hypercalcemia. Serum retinol levels can be helpful in the diagnosis, but the results must be interpreted with caution since they do not always reflect total body levels. Treatment involves supportive care and withdrawal of vitamin A sources, especially preformed ones. Given the long half-life of retinol, normalization of serum levels can take several months.

\section{KEY POINTS}

Vitamin A is present in two forms, ie, preformed (retinoids) or as a precursor (carotenoids).

Vitamin A toxicity occurs only from over-ingestion of preformed vitamin A, found in animal sources, supplements, and medications, because absorption of preformed vitamin $A$ is under minimal regulation at the level of the small intestine.

Acute vitamin A toxicity can present with multisystem manifestations including hepatic, neurologic, skin, mucous membrane, and musculoskeletal damage.

Chronic ingestion of vitamin A beyond the recommended daily amount can be associated with increased bone resorption, reduced bone formation, hypercalcemia, and increased risk of fractures.

doi:10.3949/ccjm.89a.21056
V ITAMIN A TOXICITY IS OFTEN overlooked in the diagnostic evaluation of hypercalcemia, which itself is often detected incidentally during unrelated laboratory testing. ${ }^{1,2}$ The diagnostic evaluation of hypercalcemia starts with establishing the role of parathyroid hormone (PTH) in its pathogenesis. An elevated PTH level may indicate primary hyperparathyroidism, tertiary hyperparathyroidism, or familial hypocalciuric hypercalcemia. A low PTH should trigger an evaluation for hypercalcemia induced by PTH-related peptide (PTHrP). Vitamin A toxicity should be considered in the diagnostic workup along with malignancy, bone metastasis, vitamin D or calcium toxicity, increased 1,25-hydroxyvitamin D production (eg, from granulomatous disorders and lymphomas), hyperthyroidism, monoclonal gammopathy, and immobility. ${ }^{3}$

In this article, we explore vitamin A toxicity in the differential diagnosis of hypercalcemia.

\section{A CASE SCENARIO: AN ELDERLY WOMAN WITH HYPERCALCEMIA}

An elderly woman presented to our outpatient endocrinology practice with mild asymptomatic hypercalcemia. She reported taking 2 different multivitamin tablets for many years. On laboratory testing, her PTH level was suppressed, PTHrP was normal, 1,25-hydroxyvitamin D and thyroid function tests were normal, and serum and urine electrophoresis did not reveal monoclonal gammopathy (Table 1). She was not taking any prescription medications that could cause hypercalcemia.

After an extensive workup, her serum vitamin A (retinol) levels were found to be elevated to almost twice the upper limit of normal, indicating vitamin A toxicity. Her multivita- 


\section{TABLE 1}

\section{Results of initial laboratory tests}

Comprehensive metabolic panel

Value $^{\mathrm{a}}$

Reference range

Protein

$7.2 \mathrm{~g} / \mathrm{dL}$

$6.3-8.0$

Albumin

$4.6 \mathrm{~g} / \mathrm{dL}$

$3.9-4.9$

Calcium

$10.6 \mathrm{mg} / \mathrm{dL}$

8.5-10.2

Bilirubin

$0.7 \mathrm{mg} / \mathrm{dL}$

$0.2-1.3$

Alkaline phosphatase

$77 \mathrm{U} / \mathrm{L}$

34-123

Aspartate aminotransferase

$26 \mathrm{U} / \mathrm{L}$

13-35

Alanine aminotransferase

$24 \mathrm{U} / \mathrm{L}$

7-38

Glucose

$155 \mathrm{mg} / \mathrm{dL}$

74-99

Blood urea nitrogen

$23 \mathrm{mg} / \mathrm{dL}$

7-21

Creatinine

$1.08 \mathrm{mg} / \mathrm{dL}$

$0.58-0.96$

Sodium

$138 \mathrm{mmol} / \mathrm{L}$

136-144

Potassium

$4.0 \mathrm{mmol} / \mathrm{L}$

$3.7-5.1$

Chloride

$104 \mathrm{mmol} / \mathrm{L}$

97-105

Bicarbonate

$21 \mathrm{mmol} / \mathrm{L}$

22-30

Preformed

Parathyroid hormone (PTH), intact

$14 \mathrm{pg} / \mathrm{mL}$

15-65

vitamin A

Calcium, ionized

$1.42 \mathrm{mmol} / \mathrm{L}$

$1.08-1.30$

retinoids

Vitamin D (25 hydroxy)

$38.2 \mathrm{ng} / \mathrm{mL}$

31-80

Vitamin $D$ (1,25 dihydroxy)

$29.7 \mathrm{pg} / \mathrm{mL}$

15-60

from animal

PTH-related peptide

$<2.0 \mathrm{pmol} / \mathrm{L}$

$0.0-3.4$

Thyroid stimulating hormone

$1.1 \mu \mathrm{U} / \mathrm{mL}$

$0.27-4.2$

Vitamin A/retinol

$1.99 \mathrm{mg} / \mathrm{L}$

$0.3-1.2$

Protein electrophoresis urine

Protein electrophoresis serum

a Significant values are in boldface.

No definitive $M$ protein identified

No definitive M protein identified

mins were discontinued, resulting in improved retinol and calcium levels several months later.

\section{PREFORMED VS PRECURSOR VITAMIN A}

Vitamin A supports the integrity of epithelial cells and structural proteins across the human body. It also has a role in normal cellular immunity, supporting the functions of natural killer cells and macrophages. It is vital for vi- sion and is especially important in pregnancy, as it contributes to organogenesis during early fetal development. ${ }^{4-8}$

Vitamin A is the term applied to a group of fat-soluble retinoids - retinol, retinal, and retinyl esters. Vitamin A can be ingested as preformed molecules (activated vitamin A), or as vitamin A precursors ("provitamin A") called carotenoids, which the body converts to reti- 


\section{TABLE 2}

\section{Vitamin A in various food products and over-the-counter supplements, ranked by \% RDI}

\begin{tabular}{|c|c|c|c|}
\hline Food product or supplement & Form of vitamin $A$ & $\begin{array}{l}\text { Vitamin A content } \\
\text { ( } \mu \mathrm{g} \mathrm{RAE})\end{array}$ & $\begin{array}{l}\text { Percentage of } \\
\text { RDI for adult men }\end{array}$ \\
\hline Beef liver, 3 ounces & Activated (preformed) & 6,582 & 731 \\
\hline Cod-liver oil, 1 tablespoon & Activated & 4,080 & 453 \\
\hline $\begin{array}{l}\text { Sunmark One Daily Women's } \\
\text { Multivitamin, } 1 \text { tablet }{ }^{\mathrm{a}}\end{array}$ & $\begin{array}{l}\text { Mixed }(80 \% \text { activated, } \\
20 \% \text { provitamin } \mathrm{A})\end{array}$ & 2,500 & 277 \\
\hline Sweet potato, 1 whole & Provitamin A & 1,403 & 156 \\
\hline Centrum Silver Adults, 1 tablet & $\begin{array}{l}\text { Mixed }(60 \% \text { activated, } \\
40 \% \text { provitamin } A)\end{array}$ & 750 & 83 \\
\hline $\begin{array}{l}\text { One A Day, Women's Complete } \\
\text { Multivitamin }\end{array}$ & $\begin{array}{l}\text { Mixed }(90 \% \text { activated, } \\
10 \% \text { provitamin } A)\end{array}$ & 700 & 78 \\
\hline Spinach, $1 / 2$ cup & Provitamin A & 573 & 64 \\
\hline Ricotta cheese, part skim, 1 cup & Activated & 263 & 31 \\
\hline Egg, boiled, 1 large & Activated & 75 & 8 \\
\hline Broccoli, $1 / 2$ cup & Provitamin A & 60 & 7 \\
\hline Yogurt, 1 cup & Activated & 32 & 4 \\
\hline Chicken meat, $1 / 2$ breast piece & Activated & 5 & 1 \\
\hline
\end{tabular}

noids. ${ }^{4,5}$ Preformed vitamin $\mathrm{A}$ is derived naturally from animal products such as dairy, fish oils, eggs, liver, and meat, whereas carotenoids occur naturally in plant-based foods such as carrots, sweet potatoes, and pumpkins. ${ }^{4-6}$ Preformed vitamin $\mathrm{A}$ and carotenoids can be found in the same over-the-counter (OTC) products and in prescription medications such as isotretinoin and tretinoin. If a supplement contains both preformed vitamin $\mathrm{A}$ and carotenoids, the ratio is usually reported on the ingredient label on the back of the bottle.

\section{THE ROLE OF ABSORPTION IN VITAMIN A TOXICITY}

Vitamin A toxicity results from excessive intake of preformed vitamin $A$, not from expo- sure to vitamin A precursors because of the way absorption of these substances is regulated at the level of the gut. 4,5,9,10

Absorption of vitamin A occurs in the lumen of the small intestine. It is picked up in the duodenum by micelles formed with the aid of bile acids released from the gallbladder. ${ }^{4-6,9,10}$ Retinoids are hydrolyzed further and converted to retinol, and retinol uptake is facilitated through the brush border of the small intestine via transport proteins.

The efficiency of absorption of preformed vitamin A through gut transport proteins is high — in the range of $70 \%$ to $90 \%$ — and does not vary based on the ingested amount. Carotenoids, on the other hand, are not transported by carriers but by passive diffusion across the

\section{Vitamin A toxicity results from excessive intake of preformed vitamin A}




\section{TABLE 3}

\begin{tabular}{|c|c|c|}
\hline Age & $\begin{array}{l}\text { Sex, } \\
\text { subpopulations }\end{array}$ & $\begin{array}{l}\text { Recommended daily } \\
\text { intake of vitamin A } \\
\text { ( } \mu \mathrm{g} \text { RAE) }\end{array}$ \\
\hline $0-6$ months & Male and female & $400^{a}$ \\
\hline 7-12 months & Male and female & $500^{\mathrm{a}}$ \\
\hline $1-3$ years & Male and female & 300 \\
\hline $4-8$ years & Male and female & 400 \\
\hline 9-13 years & Male and female & 600 \\
\hline 14 years or older & Male & 900 \\
\hline 14 years or older & Female & 700 \\
\hline 14-18 years & Female - pregnant & 750 \\
\hline 14-18 years & Female - lactating & 1,200 \\
\hline 19-50 years & Male & 900 \\
\hline $19-50$ years & Female & 700 \\
\hline 19-50 years & Female - pregnant & 770 \\
\hline 19-50 years & Female - lactating & 1,300 \\
\hline
\end{tabular}

${ }^{a}$ Value extrapolated from vitamin A content of consumed breast milk by healthy infants. $\mathrm{RAE}=$ retinol activity equivalents

Based on information in references 4 and 5.

luminal border, and this results in poor absorption efficiency, in the range of $9 \%$ to $22 \%$. In addition, upon ingestion of excessive amounts of carotenoids, the efficiency of luminal diffusion decreases, which further protects against toxicity from over-ingestion. Based on this, OTC vitamins containing carotenoids may be safer for patients than those containing preformed vitamin A. ${ }^{11}$ The patient described in our case scenario was taking a supplement with vitamin A content that was above the recommended daily intake (RDI).

Once absorbed, most vitamin A is stored in the liver and released into the bloodstream, where retinol-binding protein transports it to its target tissues. ${ }^{12}$ If the body's supply of vitamin A changes, the liver modifies the release of retinol into the serum to maintain normal plasma retinol levels. However, a normal plasma retinol level does not always indicate normal total body levels of vitamin $A$, and low or high retinol levels can indicate a significant abnormality of the body's vitamin A stores. ${ }^{12,13}$ The half-life of vitamin $A$ is estimated to be 128 days, so it can take many months for retinol levels to normalize after vitamin A toxicity. ${ }^{4}$

\section{CHALLENGES TO APPROPRIATE VITAMIN A INTAKE}

OTC supplements are the most common source of clinically significant preformed vitamin A ingestion. In a national survey, approximately half of the US population reported using an OTC supplement, with $28 \%$ to $37 \%$ reporting using a multivitamin that contains vitamin $A$ and with a higher proportion in the elderly. ${ }^{14}$ This high percentage of use is concerning, given that multivitamin products are not under US Food and Drug Administration regulation, and reported vitamin ingredients are often inaccurate and underestimated. ${ }^{15}$ Manufacturers can sell vitamins OTC, often with quantities above the recommended daily intake, and packaging, flavoring, and chewable formulations make the products more desirable, increasing the risk of vitamin A toxicity in children. ${ }^{16}$

The proposed standardized measure for vita$\min \mathrm{A}$ is retinol activity equivalents (RAE) in micrograms. The RDI of vitamin A is $900 \mu \mathrm{g}$ RAE for men and $700 \mu \mathrm{g}$ RAE for women. ${ }^{4-6}$ The RDI for children varies with age but can range from $300 \mu$ gAE to $700 \mu g$ RAE. 4,5 Table 2 shows vitamin A content in different food products and supplements and compares them with the RDI., ${ }^{517-20}$ Table 3 shows the RDI of vitamin $\mathrm{A}$ based on sex and age groups. ${ }^{4,5}$

\section{CONSEQUENCES OF EXCESSIVE VITAMIN A INTAKE}

The tolerable upper daily intake level of vitamin A is approximately 3,000 $\mu \mathrm{g}$ RAE. ${ }^{4}$ Higher levels increase the risk of vitamin A-induced chronic liver damage and fetal teratogenicity. ${ }^{21-24}$ Importantly, chronic daily ingestion of preformed vitamin $\mathrm{A}$ above the recommended intake (700 to $900 \mu \mathrm{g}$ RAE) but below the tolerable upper intake $(3,000 \mu \mathrm{g}$ RAE) may still be harmful, especially to the musculoskeletal system..$^{5,25,26}$ 
Acute ingestion (ie, a single dose) of more than $200,000 \mu \mathrm{g}$ RAE of preformed vitamin $\mathrm{A}$ is required to cause acute hypervitaminosis $\mathrm{A}$ syndrome in adults. ${ }^{6}$ This condition is uncommon and was seen historically in Atlantic explorers who inadvertently ate large amounts of animal livers containing preformed vitamin A., ${ }^{5,10}$

Acute over-ingestion of vitamin A can affect multiple systems:

- Neurologic-increased intracranial pressure, headaches, dizziness, vomiting, delirium, and confusion

- Hepatobiliary-nausea, vomiting, and jaundice resulting from hepatitis progressing to cirrhosis

- Musculoskeletal-periosteal bone resorption, osteopenia, elevated alkaline phosphatase, and hypercalcemia

- Skin and mucous membranes-dry, fragile skin, brittle nails, loss of hair. ${ }^{10,27}$

In clinical practice, however, chronic over-ingestion of vitamin $\mathrm{A}$ is a much more likely cause of vitamin A toxicity.

\section{VITAMIN A AND THE SKELETON: BONE RESORPTION AND HYPERCALCEMIA}

The mechanism of vitamin A-induced bone resorption and hypercalcemia is poorly understood. It is hypothesized to be secondary to increased osteoclastic activity, reduced osteoid, suppression of osteoblastic activity, and hormonal dysregulation of calcium homeostasis of parathyroid hormone and vitamin D. ${ }^{28-31}$ Vitamin A and vitamin D exhibit a complex relationship that occurs at the molecular transcription level, where they can have stimulatory or inhibitory effects on each other. ${ }^{32-35}$ However, the effects of vitamin A toxicity on bone resorption have been observed independent of serum calcium, phosphate, and vitamin D levels. ${ }^{36}$

Results of studies in humans are consistent with those of animals. In a study of 39 pediatric patients treated for neuroblastoma with a high-dose vitamin A derivative, hypercalcemia developed in twelve (31\%) patients. ${ }^{37}$ In a study of adult patients treated for multiple myeloma with all-trans retinoic acid, hypercalcemia was observed in 3 of 6 patients treated. ${ }^{38}$ Myalgia, arthralgia, and skeletal pain were consistently seen in a case series of patients di- agnosed with hypervitaminosis A syndrome. ${ }^{39}$

Animal studies have shown an increased incidence of bone fractures with exposure to large amounts of vitamin A. ${ }^{40}$ In humans, even if the ingestion of preformed vitamin $\mathrm{A}$ is increased moderately and incrementally over a long period, skeletal manifestations may occur. In cross-sectional and nested-control studies conducted in 2 counties in Sweden, each 1,000- $\mu \mathrm{g}$ RAE increment intake of daily

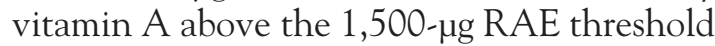
was associated with a $68 \%$ increase in the risk of hip fracture. ${ }^{25}$

In a US study, ${ }^{26}$ a prospective cohort of 72,337 nurses was followed for 18 years. Those who ingested more than 2,000 $\mu \mathrm{g}$ RAE of vitamin A daily had almost double the risk of hip fracture compared with those who ingested less than $500 \mu \mathrm{g} \mathrm{RAE}^{26}$ In another prospective cohort of postmenopausal women followed for a mean duration of 9.5 years in the United States ${ }^{41}$ the risk of hip fracture was 1.18 times greater in those who used a vitamin A-containing supplement, although the difference did not reach statistical significance $(95 \%$ confidence interval 0.99-1.41). In a longitudinal cohort of 2,322 men followed for a median of 30 years, ${ }^{42}$ a baseline serum retinol level in the upper quartiles was associated with a significantly higher risk of hip fracture and all fractures.

\section{TREATMENT RELIES ON ANECDOTAL EXPERIENCE}

Treatment of vitamin A toxicity is based on anecdotal data from case reports. ${ }^{6,36-38}$ The recommendation is to withdraw sources of vitamin A, especially of preformed vitamin A, and provide standard supportive treatment for multisystem manifestations. Limited data are available regarding the role of antiresorptive agents in treating vitamin A-related skeletal adverse effects and hypercalcemia. With discontinuation of vitamin $\mathrm{A}$ ingestion, retinol and calcium levels are expected to improve within weeks to months, although longitudinal prognostic data are limited.

\section{TAKE-HOME MESSAGE: CONSIDER VITAMIN A IN HYPERCALCEMIA}

Consumption of plant-derived precursor vitamin A (carotenoids) is harmless, but excessive

\section{Absorption of preformed vitamin A through gut transport proteins is highly efficient}


consumption of preformed vitamin A commonly found in OTC supplements and some animal products can have negative multisystem manifestations. Vitamin A is an often overlooked cause of hypercalcemia, thought to stem from its adverse effect on the skeletal system through stimulation of bone resorption and inhibition of bone formation. In the setting of unexplained PTH-independent hypercalcemia, serum retinol levels should be checked but interpreted with caution, as they do not always reflect total body levels. Treatment involves withdrawal of vitamin A sources and supportive care. Given the long halflife of retinol, normalization can take several months.

\section{DISCLOSURES}

The authors report no relevant financial relationships which, in the context of their contributions, could be perceived as a potential conflict of interest.

\section{REFERENCES}

1. Kuchay MS, Farooqui KJ, Jevalikar G, Mithal A. The changing profile of hypercalcemia in hospital populations. Clin Rev Bone Miner Metab 2017; 15(2):82-89. doi:10.1007/s12018-017-9231-y

2. Catalano A, Chilà D, Bellone F, et al. Incidence of hypocalcemia and hypercalcemia in hospitalized patients: is it changing? J Clin Transl Endocrinol 2018; 13:9-13. doi:10.1016/j.jcte.2018.05.004

3. Carroll MF, Schade DS. A practical approach to hypercalcemia. Am Fam Physician 2003; 67(9):1959-1966. pmid:12751658

4. Institute of Medicine (US) Panel on Micronutrients. Dietary reference intakes for vitamin $\mathrm{A}$, vitamin $\mathrm{K}$, arsenic, boron, chromium, copper, iodine, iron, manganese, molybdenum, nickel, silicon, vanadium, and zinc. Washington, DC: National Academies Press (US); 2001.

5. National Institutes of Health: Office of Dietary supplements. Vitamin A: fact sheet for health professionals. https://ods.od.nih.gov/ factsheets/VitaminA-HealthProfessional/. Accessed January 20, 2022

6. Pazirandeh S, Burns DL. Overview of vitamin A. UpToDate. https:// www-uptodate-com.ccmain.ohionet.org/contents/overview-of-vitamin-a?search=Overview\%20of\%20vitamin \%20A\&source=search_re sult\&selectedTitle=1 150\&usage_type=default\&display_rank=1. Accessed January 20, 2022.

7. Saari JC. Vitamin A metabolism in rod and cone visual cycles. Annu Rev Nutr 2012; 32:125-145.

doi:10.1146/annurev-nutr-071811-150748

8. Morriss-Kay GM, Sokolova N. Embryonic development and pattern formation. FASEB J 1996; 10(9):961-968. doi:10.1096/fasebj.10.9.8801178

9. Harrison EH. Enzymes catalyzing the hydrolysis of retinyl esters. Biochim Biophys Acta 1993; 1170(2):99-108. doi:10.1016/0005-2760(93)90058-h

10. Biesalski HK. Comparative assessment of the toxicology of vitamin A and retinoids in man. Toxicology 1989; 57(2):117-161. doi:10.1016/0300-483x(89)90161-3

11. Grune T, Lietz G, Palou A, et al. Beta-carotene is an important vitamin A source for humans. J Nutr 2010; 140(12):2268S-2285S. doi:10.3945/jn.109.119024

12. Greaves RF, Woollard GA, Hoad KE, et al. Laboratory medicine best practice guideline: vitamins $A, E$ and the carotenoids in blood. Clin Biochem Rev 2014; 35(2):81-113. pmid:25210208

13. de Pee S, Dary O. Biochemical indicators of vitamin A deficiency: serum retinol and serum retinol binding protein. J Nutr 2002; 132 (9 suppl):2895S-2901S. doi:10.1093/jn/132.9.2895S

14. Bailey RL, Gahche JJ, Lentino CV, et al. Dietary supplement use in the United States, 2003-2006. J Nutr 2011; 141(2):261-266. doi:10.3945/jn.110.133025

15. Andrews KW, Roseland JM, Gusev PA, et al. Analytical ingredient content and variability of adult multivitamin/mineral products: national estimates for the Dietary Supplement Ingredient Database. Am J Clin Nutr 2017; 105(2):526-539. doi:10.3945/ajcn.116.134544

16. Lam HS, Chow CM, Poon WT, et al. Risk of vitamin A toxicity from candy-like chewable vitamin supplements for children. Pediatrics 2006; 118(2):820-824. doi:10.1542/peds.2006-0167
17. US Department of Agriculture. FoodData Central. https://fdc.nal. usda.gov/. Accessed January 20, 2022.

18. GlaxoSmithKline. Centrum silver adults. https://www.centrum.com/ products/multivitamins/centrum-silver-adults-50-plus/. Accessed January 20, 2022.

19. One A Day. Women's complete multivitamin supplement. https:// www.oneaday.com/vitamins/vitamins-for-women/multivitamin-forwomen. Accessed January 20, 2022.

20. Sunmark. Sunmark one daily women's multivitamin/multimineral. https://commonfinds.com/products/sunmark-one-dailywomens-multivitamin-multimineral-100-tablets-1-pack-each-bysunmark? variant=32498280693857. Accessed January 20, 2022.

21. Institute of Medicine (US) Panel on Dietary Antioxidants and Related Compounds. Dietary reference intakes for vitamin C, vitamin E, selenium, and carotenoids. Washington, DC: National Academies Press (US); 2000.

22. Soprano DR, Soprano KJ. Retinoids as teratogens. Annu Rev Nutr 1995; 15:111-132. doi:10.1146/annurev.nu.15.070195.000551

23. Penniston KL, Tanumihardjo SA. The acute and chronic toxic effects of vitamin A. Am J Clin Nutr 2006; 83(2):191-201. doi:10.1093/ajcn/83.2.191

24. Hathcock JN, Hattan DG, Jenkins MY, McDonald JT, Sundaresan PR, Wilkening VL. Evaluation of vitamin A toxicity. Am J Clin Nutr 1990; 52(2):183-202. doi:10.1093/ajcn/52.2.183

25. Melhus H, Michaëlsson $\mathrm{K}$, Kindmark A, et al. Excessive dietary intake of vitamin $A$ is associated with reduced bone mineral density and increased risk for hip fracture. Ann Intern Med 1998; 129(10):770-778. doi:10.7326/0003-4819-129-10-199811150-00003

26. Feskanich D, Singh V, Willett WC, Colditz GA. Vitamin A intake and hip fractures among postmenopausal women. JAMA 2002; 287(1):47-54. doi:10.1001/jama.287.1.47

27. Geubel AP, De Galocsy C, Alves N, Rahier J, Dive C. Liver damage caused by therapeutic vitamin A administration: estimate of doserelated toxicity in 41 cases. Gastroenterology 1991; 100(6): 1701-1709. doi:10.1016/0016-5085(91)90672-8

28. Frankel TL, Seshadri MS, McDowall DB, Cornish CJ. Hypervitaminosis A and calcium-regulating hormones in the rat. J Nutr 1986; 116(4):578-587. doi:10.1093/jn/116.4.578

29. Hough S, Avioli LV, Muir H, et al. Effects of hypervitaminosis A on the bone and mineral metabolism of the rat. Endocrinology 1988; 122(6):2933-2939. doi:10.1210/endo-122-6-2933

30. Olson JA. Serum levels of vitamin A and carotenoids as reflectors of nutritional status. J Natl Cancer Inst 1984; 73(6):1439-1444. pmid:6439934

31. Scheven BA, Hamilton NJ. Retinoic acid and 1,25-dihydroxyvitamin D3 stimulate osteoclast formation by different mechanisms. Bone 1990; 11(1):53-59. doi:10.1016/8756-3282(90)90072-7

32. Metz AL, Walser MM, Olson WG. The interaction of dietary vitamin $A$ and vitamin $D$ related to skeletal development in the turkey poult. J Nutr 1985; 115(7):929-935. doi:10.1093/jn/115.7.929

33. Carlberg C, Saurat JH. Vitamin D-retinoid association: molecular basis and clinical applications. J Investig Dermatol Symp Proc 1996; 1(1):82-86. pmid:9627699

34. Joo NS, Yang SW, Song BC, Yeum KJ. Vitamin A intake, serum 
vitamin $\mathrm{D}$ and bone mineral density: analysis of the Korea National Health and Nutrition Examination Survey (KNHANES, 2008-2011). Nutrients 2015; 7(3):1716-1727. doi:10.3390/nu7031716

35. Jimenez-Lara AM, Aranda A. Interaction of vitamin D and retinoid receptors on regulation of gene expression. Horm Res 2000; 54(5-6):301-305. doi:10.1159/000053276

36. Kindmark A, Rollman O, Mallmin H, Petrén-Mallmin M, Ljunghall $\mathrm{S}$, Melhus $\mathrm{H}$. Oral isotretinoin therapy in severe acne induces transient suppression of biochemical markers of bone turnover and calcium homeostasis. Acta Derm Venereol 1998; 78(4):266-269. doi:10.1080/000155598441837

37. Villablanca JG, Khan AA, Avramis VI, Reynolds CP. Hypercalcemia: a dose-limiting toxicity associated with 13-cis-retinoic acid. Am J Pediatr Hematol Oncol 1993; 15(4):410-415. pmid:8214363

38. Niesvizky R, Siegel DS, Busquets $X$, et al. Hypercalcaemia and increased serum interleukin- 6 levels induced by all-trans retinoic acid in patients with multiple myeloma. Br J Haematol 1995; 89(1):
217-218. doi:10.1111/j.1365-2141.1995.tb08936.x

39. Frame B, Jackson CE, Reynolds WA, Umphrey JE. Hypercalcemia and skeletal effects in chronic hypervitaminosis A. Ann Intern Med 1974; 80(1):44-48. doi:10.7326/0003-4819-80-1-44

40. Wolbach SB, Hegsted DM. Hypervitaminosis A and the skeleton of growing chicks. AMA Arch Pathol 1952; 54(1):30-38. pmid:14932587

41. Lim LS, Harnack LJ, Lazovich D, Folsom AR. Vitamin A intake and the risk of hip fracture in postmenopausal women: the lowa Women's Health Study. Osteoporos Int 2004; 15(7):552-559. doi:10.1007/s00198-003-1577-y

42. Michaëlsson $K$, Lithell $H$, Vessby $B$, Melhus $H$. Serum retinol levels and the risk of fracture. N Engl J Med 2003; 348(4):287-294. doi:10.1056/NEJMoa021171

Address: Vinni Makin, MD, FACE, Department of Endocrinology, Diabetes, and Metabolism, F20, Cleveland Clinic, 9500 Euclid Avenue, Cleveland, $\mathrm{OH}$ 44195; makinv@ccf.org 